\title{
NOTA DEL XII CONGRESO LATINOAMERICANO DE BOTÁNICA, QUITO, ECUADOR, 2018
}

\section{Note of the XII Latin American Congress of Botany, Quito, Ecuador, 2018}

\section{Humfredo Marcano Vega \\ Biólogo Investigador. Programa de Inventario \\ y Análisis Forestal del Servicio Forestal del \\ Departamento de Agricultura de los Estados Unidos \\ de América, con estación de labores en el Instituto \\ Internacional de Dasonomía Tropical, Jardín \\ Botánico Sur, San Juan, Puerto Rico \\ Correo-e: humfredo.marcano@usda.gov}

\section{Lemuel Familia}

Ministerio de Medio Ambiente y Recursos

Naturales, Av. Cayetano Germosén, esq. Av.

Gregorio Luperón, Sector El Pedregal, Santo

Domingo, República Dominicana

Recibido: 13/5/2019 • Aprobado: 20/5/2019

Cómo citar: Marcano Vega, H., \& Familia, L. (2019). Nota del XII Congreso Latinoamericano de Botánica, Quito, Ecuador, 2018. Ciencia, Ambiente y Clima, 2(1), 47-48. doi: https://doi.org/10.22206/cac.2019.v2i1.pp47-48

En un momento histórico, en que iniciativas a nivel global se han puesto en marcha para describir los tipos de vegetación existentes alrededor del mundo se celebró el XII Congreso Latinoamericano de Botánica en la ciudad de Quito, Ecuador del 21 al 28 de octubre de 2018. Este congreso se realiza cada cuatro años en diferentes países de América Latina, el mismo se destaca como el evento más importante de la botánica en dicha región. Más de 600 botánicos del continente americano y otras regiones del mundo se dieron cita para el ofrecimiento de conferencias magistrales, simposios, presentaciones orales, carteles, talleres, cursos, mesas redondas, reuniones, y excursiones científicas afines con la ecología, diversidad, conservación de las plantas, sistemática, filogenética, biología molecular, etnobotánica y la educación. Dicha programación sumó a más de 1,500 participantes internacionales incluyendo científicos, estudiantes y el público general.
Un repaso de las conferencias magistrales ofrecidas es muestra del carácter internacional y distinción de los conferencistas invitados, asimismo, de la variedad de los temas abordados durante el evento; al respecto, podemos destacar a Tod Stuessy (Departamento de Ecología y Evolución de la Universidad del Estado de Ohio, EE. UU) quien disertó sobre las oportunidades y retos en la investigación de la sistemática y evolución vegetal en América Latina, resaltando que el $29 \%$ de la flora mundial es de origen latinoamericana. Jorge Crisci (Museo de la Plata, Argentina) sostuvo un conversatorio titulado "El fin de la botánica", exhortando a recapacitar sobre el propósito de las ciencias y la desesperanza que pudiera deparar el futuro a la botánica como disciplina científica. Danna J. Leaman (Museo de la Naturaleza Canadiense y Grupo de Especialistas en Plantas Medicinales, Unión Internacional para la Conservación de la Naturaleza (UICN), conferenció sobre el vínculo 
fundamental y trascendente entre las plantas y la sociedad. Fausto Sarmiento (ecólogo ecuatoriano en la Universidad de Georgia, EE. UU), ofreció una revisión sobre los paradigmas de la geografía botánica exponiendo cómo la entrada de perspectivas latinoamericanas en dicho campo de investigación está transformando el concepto de paisaje como un nuevo modelo biocultural que integra aspectos socioecológicos. Ernesto Medina (Centro de Ecología, Instituto Venezolano para la Investigación Científica), destacó la importancia y repercusión de la toma de datos empíricos sobre ecofisiología para el entendimiento de las adaptaciones de las plantas a diferentes tipos de ecosistemas como los de afloramiento calcáreo en el Caribe. Otras conferencias magistrales incluyeron a David Neil (Universidad Estatal Amazónica, Ecuador), Katya Romoleroux (Herbario de la Pontificia Universidad Católica del Ecuador), Monica Carlsen (Missouri Botanical Garden, EE. UU), Lucia Lohmann (Universidad de Sao Paulo, Brasil) y Pamela Soltis (Museo de Historia Natural de Florida, Universidad de Florida, EE. UU), abarcando temas sobre la diversidad vegetal y la conservación en ecosistemas andinos y ecuatorianos, los recientes avances tecnológicos en plantas como herramientas útiles para la investigación, la filogenia y la evolución de angiospermas.

La inclusión de expertos en botánica del Caribe ofreció la oportunidad de posicionar a diversas instituciones de la región como parte de la gran contribución científica proporcionada durante el congreso, mostrando a una audiencia internacional cómo el trabajo de investigación y la experiencia caribeńa ofrecen un escenario común para la discusión de los atributos ecológicos de la flora, la conservación de la biodiversidad y los aspectos socioculturales vinculados a la botánica. Las presentaciones orales y carteles entregados por botánicos de Cuba, República Dominicana y Puerto Rico ofrecieron temas de actualidad internacional como la distribución, la ecología, el estado de conservación de plantas autóctonas a diferentes niveles taxonómicos, plantas endémicas y epífitas, botánica económica, historia de la botánica, algas parasíticas, iniciativas noveles en la educación botánica, redes caribeñas de datos de inventario y seguimiento de plantas, rendimiento de cultivos agrícolas, la diversidad genética, filogenia y evolución de plantas, y los efectos de las plantas introducidas. En el panorama actual de cambio climático, congresos de esta magnitud logran promover y fortalecer alianzas indispensables entre distintos campos científicos e instituciones para un futuro caracterizado por la adaptación, mitigación y solidaridad a nivel mundial.

Para mayor información sobre el evento y las actividades puede consultarse este enlace: https://clb2018. org/quito-sera-sede-del-xii-congreso-latinoamericano-de-botanical 